\title{
Predictors of pulmonary hypertension in obstructive sleep apnoea syndrome
}

\section{To the Editor:}

I have read with much interest the paper by LAKS et al. [1] on pulmonary hypertension (PHT) in obstructive sleep apnoea (OSA), in which there is new evidence that daytime PHT can exist without daytime hypoxaemia in OSA.

Finding predictors of the existence of PHT in these normoxaemic patients may have important practical consequences. However, in their general series the authors [1] find that only daytime arterial oxygen tension $\left(\mathrm{Pa}_{\mathrm{a}} \mathrm{O}_{2}\right)$, arterial carbon dioxide tension $\left(\mathrm{Pa}_{\mathrm{a}} \mathrm{CO}_{2}\right)$, and forced expiratory volume in one second ( $\mathrm{FEV} 1)$, are statistically significant predictors of PHT (however, since the coefficients of correlation have low values and, as is stated by the authors, $67 \%$ of the variability is left unexplained if these variables are considered, one may wonder whether it actually has any clinical importance).

It is surprising that no index of severity of OSA is correlated with PHT, which goes against previously published studies and against what one could expect to be "logical". Perhaps it is true that, as is stated by LAKS et al. [1], the apnoea/hypopnoea index (AHI) and the respiratory disturbance index (RDI) do not accurately represent hypoxaemic exposure (and, hence, the severity of OSA). However, I think three points must be discussed: 1. Severity of OSA is defined by RDI, not by AHI. Since RDI is not defined, one cannot know if it is the same as AHI, or whether both indices can be made equal without error. Since RDI has been defined by other authors as comprising apnoeas longer than $10 \mathrm{~s}$ as well as other events with a shorter duration [2], perhaps it overestimates the severity of OSA (there can be desaturations associated with snoring without apnoea [3]), and so AHI should be used to define the severity of OSA. 2. Apnoeas/hypopnoeas are not described as they usually are, with a duration of at least $10 \mathrm{~s}$ [4-8]. The definition the authors give for apnoea and hypopnoea [1] may include situations that would not otherwise be described as apnoeas or hypopnoeas (since their duration is shorter than $10 \mathrm{~s}$ ), thus overestimating the severity of OSA.

3. The authors stress the need for indices of exposure to hypoxaemia and hypercapnia. In this sense, several indices have been proposed that could be used as markers of hypoxaemic stress (and in fact some of them have been used for this purpose) in addition to minimal arterial oxygen saturation $\left(\mathrm{Sa}_{2} \mathrm{O}_{2}\right)$ : a) mean $[4,9]$ or median [7] $\mathrm{Sa}_{\mathrm{a}} \mathrm{O}_{2}$ during sleep; b) mean $\mathrm{Sa}_{\mathrm{a}} \mathrm{O}_{2}$ of abnormal respiratory patterns [7]; c) number of desaturations under $85 \%$, which has been called "severity index" [10]; d) sleep time (or fraction of total sleep time (TST)) spent at each level of $\mathrm{Sa}_{\mathrm{a}} \mathrm{O}_{2}$ [11]: under $60 \%$ [7], 70\% [7], 80\% [7], $85 \%$ [4], 90 [7, 9] or 95\% [12]; e) fraction of TST spent in each $10 \%$ interval of $\mathrm{Sa}_{2} \mathrm{O}_{2}[6,11]$ and cumulative distribution function of $\mathrm{Sa}_{2} \mathrm{O}_{2}$ [11]; f) apnoea-hypopnoea time (usually as percentage of TST) [13]; g) mean desaturation time [13]; h) desaturation index [9]; and i) nocturnal desaturation score [14].

I would like to raise one question that, in view of the thorough study LAKs et al. [1] have performed, will surely be easy to answer: Could any of the abovementioned indices (apnoeas and hypopnoeas being defined following "classical" criteria in order to assess AHI) predict the development or existence of PHT, even in normoxaemic patients?

\section{References}

1. Laks L, Lehrlaft B, Grunstein RR, Sullivan CE. Pulmonary hypertension in sleep apnoea. Eur Respir J 1995; 8: $537-541$.

2. Van Surell C, Lemaigre D, Leroy M, Foucher A, Hagenmuller MP, Raffestin B. Sensitivity and specificity of an ambulatory device in the diagnosis of obstructive sleep apnoea syndrome. Eur Respir J 1994; 7 (Suppl. 18): 202s.

3. Stradling JR. Handbook of Sleep-related Breathing Disorders. Oxford, Oxford University Press, 1993; pp. 145-157.

4. Strohl KO. Sleep apnea syndrome and sleep-disordered breathing. In: Baum GL, Wolinsky E, eds. Textbook of pulmonary diseases. Boston, Little, Brown and Co., 1994; pp. 1097-1116.

5. Guilleminault C, van der Hoed J, Mitler MM. Clinical overview of the sleep apnea syndromes. In: Guilleminault C, Dement WD, eds. Sleep Apnoea Syndromes. New York, Alan R. Liss Inc., 1978; pp. 1-12.

6. Carmona Bernal C, Capote Gil F, et al. Estudios polisomnográficos cortos en el diagnóstico del síndrome de apnea obstructiva del sueño. Arch Broncopneumol 1994; 30: 390-393.

7. The American Thoracic Society. Indications and standards for cardiopulmonary sleep studies. Am Rev Respir Dis 1989; 139: 559-568.

8. Grupo de Trabajo SEPAR. Normativa sobre diagnóstico y tratamiento del síndrome de apnea obstructiva del sueño (SAOS). Barcelona, Ediciones DOYMA, S.A., 1993.

9. Resta O, Picca V, Guido P, et al. Nocturnal oxyhaemoglobin desaturation in COPD patients with "borderline" hypoxaemia. Eur Respir J 1994; 7 (Suppl. 18): 237s.

10. Mishoe SC. The diagnosis and treatment of sleep apnea syndrome. Respir Care 1987; 32: 183-201.

11. Slutsky AS, Strohl KP. Quantification of oxygen saturation during episodic hypoxemia. Am Rev Respir Dis 1980; 121: 893-895. 
12. Ayerbe García R, Cano Gómez S, Capote Gil F, Carmona Bernal C, Hernández Utrera F, Castillo Gómez J. Factores relacionados con el desarrollo de hipercapnia (HC) en pacientes con síndrome de apnea del sueño (SAS). Arch Broncopneumol 1993; 29 (Suppl. 1): 23s.

13. Sandek K, Andersson T, Bratel T, Hellström G. Sleep quality, respiratory drive and desaturation patterns in nocturnal hypoxemia due to chronic obstructive lung disease (COLD). Eur Respir J 1994; 7 (Suppl. 18): 237s.

14. Hasday JD, Grum CM. Nocturnal increase of uric acid:creatinine ratio: a biochemical correlate of sleep-associated hypoxemia. Am Rev Respir Dis 1987; 135: 534-538.

\author{
A.D. Herranz \\ C/Puente Colgante, 28, $1^{\circ} \mathrm{D}, 47007$ Valladolid, Spain.
}

\section{REPLY}

From the authors:

We agree with Herranz that more accurate indices of sleep-related breathing disorders may correlate better with the levels of daytime pulmonary artery pressure. However, the task of finding an "index of severity" for sleep apnoea seems to be quite difficult, as suggested by the number of indices quoted by Herranz in his letter. There is not even a general agreement on noninvasive diagnosis of upper airway obstruction in sleep and the role of cortical arousals without oxyhaemoglobin desaturation on cardiovascular function.

In addition, the suggestion that we review our results and come up with this index is unfortunately impractical, as the study was conducted over a long period of time, using a number of different technologies, which would make the retrospective analysis of the data difficult.

Moreover, a number of other factors can contribute to the development of sustained pulmonary hypertension in sleep apnoea patients. One of them, which we have investigated in more detail, is the presence of between-subject variability in pulmonary artery pressure response to hypoxia, and the role hypercapnia plays in modulating this response. We have recently submitted a manuscript which summarizes our data on pulmonary artery pressure response to acute eucapnic and hypercapnic hypoxia in a group of 20 patients with moderate to severe sleep apnoea without chronic lung disease and a group of 9 healthy volunteers. Among other findings, the study showed a significant between-subject variability in the pressor response. This was true both for normal volunteers and patients with sleep apnoea, both at eucapnic and hypercapnic levels of hypoxia. The pulmonary pressor response to hypoxia and hypercapnia may be a much stronger predictor of daytime pulmonary artery pressure in patients with sleep apnoea than the severity of sleep apnoea alone.

The problem of pulmonary hypertension complicating sleep apnoea is far from solved and its demands further investigation. This knowledge can contribute in a major way to our understanding of the pathophysiology of such diverse respiratory problems as sleep apnoea, chronic airflow limitation and primary pulmonary hypertension, to name but a few.

\section{Laks}

Sidney Sleep Disorders Centre, Sidney, Australia. 